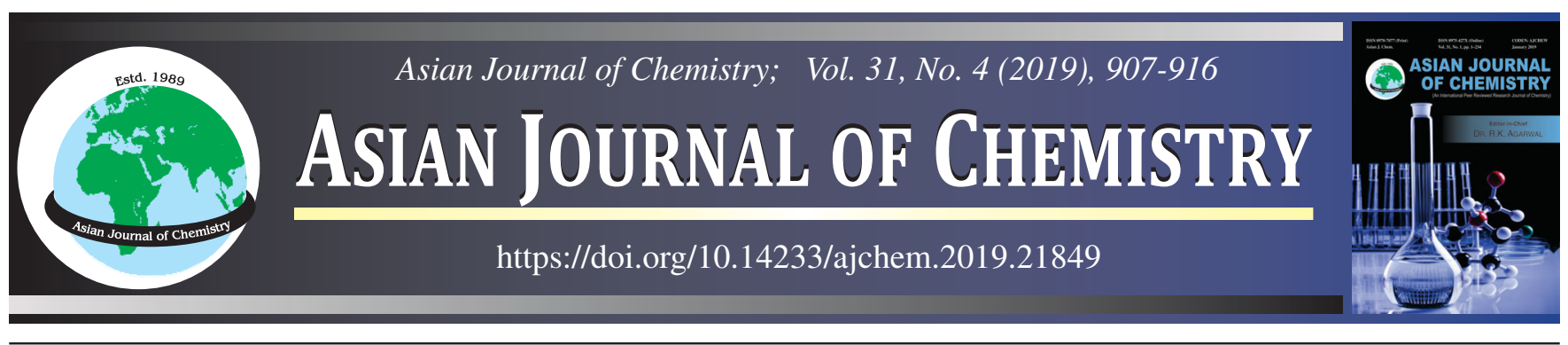

\title{
Investigations on Natural Surfactant obtained from Soap-Nuts through Spectrophotometric Interactions with Congo Red and Comparison with Commercial Surfactants
}

\author{
M.C. Somasekhara Reddy ${ }^{1,2, *}$, S.M. SARVAR JAhan ${ }^{1}$, K. SRIDEvi ${ }^{1,3}$ and G.V. Subba Reddy ${ }^{3}$
}

${ }^{1}$ Department of Basic Sciences, G.P.R. Engineering College (Autonomous), Kurnool-518007, India

${ }^{2}$ Present Address: Section of Chemistry, Department of Science and Mathematics (DESM), Regional Institute of Education (RIE), Mysore570006, India

${ }^{3}$ Department of Chemistry, Jawaharlal Nehru Technological University Engineering College, Pulivendula-516390, India

*Corresponding author: E-mail: mcsr.gprec@gmail.com; som16@rediffmail.com

Received: 27 November 2018;

Accepted: 9 January 2019;

Published online: 27 February 2019;

AJC-19306

\begin{abstract}
A natural surfactant (NS) of plant-base was obtained from the fruit pericarp of soapnuts by using a simple and economical method. The interaction of this natural surfactant with direct dye, anionic dye, Congo red (CR) was studied spectrophotometrically in sub-micellar and micelle concentration range in aqueous solution. These interactions (CR-NS) were compared with that of CR-CTAB (cationic surfactantcetyl trimethylammonium bromide, CTAB), CR-SDS (anionic surfactant-sodium dodecyl sulphate, SDS) and CR-TX 100 (neutral surfactant - Triton X-100, TX 100) and were useful to understand the nature of natural surfactant. The mechanism of formation of complex due to interactions between Congo red and natural surfactant was suggested. This spectrophotometric method was used for the determination of critical micelle concentration (CMC), at which the formation of micelles was started. The CMC values obtained spectrophotometrically for the natural surfactant was coincided with the experimental value available in the literature. A definite change in the absorbance maxima of Congo red in the presence of natural surfactant (micelles of natural surfactant) was also observed. The change in maxima was also interpreted in terms of $\mathrm{pH}$ and CMC. The equilibrium constant of interaction between Congo red and natural surfactant was calculated on the theoretical model. The stability of the complexes of Congo red with different surfactants like CTAB, SDS, TX 100 and natural surfactant may be written in increasing order as: CR-TX $100>$ CR-CTAB > CR-NS > CR-SDS. The biodegradable, non-toxic, inexpensive, environmental friendly, renewable natural surfactant was suggested in place of synthetic surfactants.
\end{abstract}

Keywords: Natural surfactant, Saponin, Soapnuts, Congo red, Equilibrium constant, Critical micelle concentration.

\section{INTRODUCTION}

Surfactant molecule consists hydrocarbon and polar or ionic portion. The hydrocarbon portion, which can be linear or branched, interacts only very weakly with the water molecules in an aqueous environment. Moreover, the strong interactions between the water molecules arising from dispersion forces and hydrogen bonding act cooperatively to squeeze the hydrocarbon out of the water, hence, the chain was usually called hydrophobic. This part was non-ionic and consists a long hydrocarbon chain. The polar or ionic portion of the molecule such as $-\mathrm{COO}^{-} \mathrm{Na}^{+}$, usually termed as the head-group, however, interacts strongly with the water via dipole-dipole or ion-dipole interactions and was solvated. Consequently, the head-group was said to be hydrophilic [1]. When a surfactant was dissolved in water, the molecules tend to cluster towards the surface such that the hydrophobic tails of the surfactant molecules were directed away while the polar parts were directed towards water [2-4].

The surface active agents were broadly classified into synthetic and natural surfactants based on the source and availability. Large amount of synthetic surfactants used for domestic and industrial work were dispersed in diverse environmental sections like soil, water, sediment etc. Some reports revealed that about $60 \%$ of the total surfactant production enters the aquatic environment [5] and these surfactants were considered as emerging pollutants of the environment [4]. For example, synthetic surfactant, alkylphenol ethoxylate surfactants and their pro-

This is an open access journal, and articles are distributed under the terms of the Creative Commons Attribution-NonCommercial-ShareAlike 4.0 (CC BY-NC-SA 4.0) International License which allows readers to freely read, download, copy, distribute, print, search, or link to the full texts of its articles and to use them for any other lawful non-commercial purpose as long as the original source is duly acknowledged. 
ducts (APEOs) were known as endocrine disrupting chemicals [6]. Like this, these non-biodegradable surfactants affect the environment and cause health hazards like dermatitis, respiratory, eye irritation etc. [7,8]. Synthetic surfactants persist in nature for longer periods due to slow degradation and the degradation products were more hazardous than the parental compounds. So these surfactants cause environmental and toxicological problems as they release carcinogenic toxins in the environment [9]. Cationic surfactants were most toxic followed by anionic and non-ionic surfactants [10]. The damaging affects of surfactants on humans, microorganisms aquatic plants, invertebrate and crustaceans also follow the same trend [11]. The worldwide large production of surfactants was increased year by year due to the technological development, ease of preparation and important applications [12]. 12.5 million tonnes of surfactants were produced worldwide in 2006 [13] whereas 3 million tonnes were produced in Western Europe in 2007 [14] and approximately 172 thousand tonnes of nonionic surfactants were consumed in 2010 in US alone [5]. Therefore, use of synthetic surfactants in various applications leads to secondary pollution. To overcome these sensitive environmental problems, a surfactant should be biodegradable and less toxic in addition to being surface active [15]. Natural surfactants were suggested as viable alternative to synthetic surfactants because these were bio-degradable, biocompatible, renewable, low cost, higher foaming capacity, highly selective and specifically active at extreme temperatures, $\mathrm{pH}$ and salinity [16] and less toxic and hence pose less threat to the environment. Natural surfactants were obtained directly from natural sources like plants, bacteria or fungi. Techniques like extraction, filtration, precipitation or distillation were used to obtain them. Some publications [17-19] revealed that fatty acid esters of sugars or amides of amino acids or humic acids from biomass could be used as natural surfactants in place of synthetic surfactants.

There are several natural surfactants reported in the literature. Plant based saponins obtained from plants were used as natural surfactants or biosurfactants. These have used significantly due to their wonderful functional properties, health benefits, environmentally safe, biodegradable, renewable and ecologically adaptable $[5,20]$. These saponins were mainly derived from various parts of plants like seed, root, leaf, fruit, pericarp, bark and flower [21-23]. Saponins were extracted from more than 100 families of plants along with few marine sources such as starfish and sea cucumber [24]. Sapindus mukorossi and Sapindus emarginatus were commonly known as reetha or soapnut fruits were major source of saponins. These trees were found in the different regions of India, Pakistan and other tropical and sub-tropical regions of the world. However, Sapindus mukorossi was abundant in the most part of northern India. This belongs to the main plant order Sapindaceae and family Sapindeae. Soapnut was round, saponaceous and fleshy nut. The fruit of soapnut tree was yellowish brown in colour and changes its colour on drying. The fruit consists of seed encapsulated in a black hard and shiny endocarp or shell and pericarp. The pericarp constitutes about $56 \%$ of the whole fruit and the rest was balanced by the seed [25]. The fruits pericarp contains saponin, which was known for the surfactant action. The saponin content in the reetha varies from 6 to 10 wt $\%$ [26]. The aqueous extract of this was traditionally used as a shampoo for cleaning hairs and as a detergent for cleaning woolen fabrics and precious ornaments [27]. It was observed that shampoo named by Meera available in the market was prepared using this extract. It was also used in medicine [28]. It was used as a component of herbal local contraceptive because it has anti-trichomonas activity [29].

The different types of saponins were available in the literature [30]. The major saponins present in the pericarp of the soapnut fruit were triterpenoid-type [31]. This triterpenoid group was considered as a hydrophobic nucleus (aglycone called sapogenin) [32]. This hydrophobic nucleus was connected to hydrophilic sugar chains through ether or ester bonds. The simultaneous presence of non-polar hydrophobic (aglycone) and polar hydrophilic (sugar) chains provide surface activity.

Saponin surfactant obtained from pericarp of soapnut fruits were used for many applications and documented in the literature. This was used for understanding the micellar characteristics of sapindus saponin and its ability to solubilize oils [33], for solubilization of dyes like methylene blue and eosin yellow [4] and neutral red [34], for preparation of platinum nanoparticles [35] and gold nanoparticles [36], for understanding surface and foam characteristics of saponins [37], in soil washing $[20,32,38,39]$, synthesis of monodisperse lattices [5], surfactant enhanced oil recovery [40], solubilization of naphthalene [41], removal of phenolic compounds [42] and for solubilization of foreign materials present in muga silk [43]. Seeds of soapnuts produce non-edible oil that can be used as biodiesel [44]. External use of saponins as a washing soap show no toxic effects on human skin and eyes [20].

In view of these excellent applications and uses of aqueous extract of pericarp of soapnuts, interest led us to understand the nature of natural saponin surfactant. Therefore, in the present investigations, the solubilization of a direct dye, Congo red (CR) (anionic dye) in presence of saponin micelles was studied and compared these results with commercial surfactants like cationic surfactant - cetyl trimethylammonium bromide (CTAB), anionic surfactant - sodium dodecyl sulphate (SDS) and neutral or non-ionic surfactant - Triton X 100 (TX 100) for understanding the nature of natural saponin. In this study, interactions of Congo red with surfactants were studied through spectrophotometric technique. This spectrophotometric data was used to find out micellar characteristics of saponin such as critical micellar concentration (CMC). The solubilization was tested at different $\mathrm{pH}$ of surfactant solutions. Further, this data was used to find out equilibrium constant between Congo red and surfactants.

\section{EXPERIMENTAL}

Soap nut pericarp powder: $3 \mathrm{~kg}$ of Soapnut fruits (Scientific Name: Sapindus mukorossi) were procured from the local market of Kurnool, India. These soapnut fruits were golden brown in colour and globular in shape with a diameter between 1 and 3 $\mathrm{cm}$. After removing the seed, the outer pericarps were dried in an oven at $50{ }^{\circ} \mathrm{C}$ for about 2 days. The dried pericarps were ground into powder by using domestic grinder and the powder 
was sieved through U.S. Standard No. 20 sieve $(840 \mu \mathrm{m})$. The soapnut pericarp powder was stored in Pearle pet (Plastic) bottles.

Congo red (m.w. 696.67 g), cetyltrimethyl ammonium bromide (CTAB), sodium dodecyl sulphate (SDS), Triton Triton X 100 (TX 100), hydrochloric acid, sodium hydroxide, potassium chloride, methanol, etc (M/s Qualigens Fine Chemicals, India) were procured. All the chemicals were of analytical grade. The Congo red was purified by using salting out method [45]. The C.I. name of Congo red (22120) was direct red 28. $\lambda_{\max }$ of Congo red was $497 \mathrm{~nm}$. The doubled distilled water was used for the preparation of solutions wherever required unless otherwise it was specified. Buffer solutions were prepared by adopting the standard procedures reported in the literature [46]. The Elico Digital pH Meter Model LI-120, M/s Elico Private Limited, India was used for measurement of $\mathrm{pH}$ of buffer solutions and test solutions.

Preparation of plant based natural surfactant solution: Based on the available literature, water, methanol, ethanol and benzene:methanol (1:3) [20] mixture was examined as solvents for preparing the natural surfactant solutions. The powder was added to solvents and stirred for $3 \mathrm{~h}$ at room temperature. The mixture was centrifuged at $10000 \mathrm{rpm}$ per $45 \mathrm{~min}$ and the supernatant was filtered through Whitman No. 1 filter paper. The filtrate was allowed to evaporate on a water bath at $70^{\circ} \mathrm{C}$. The dry paste obtained was re-dissolved in water and used as stock chemical name was solution. A $10 \%$ natural surfactant solution was prepared by extracting $10 \mathrm{~g}$ of soap-nut fruit pericarp powder in $100 \mathrm{~mL}$ of de-ionized water. In a similar way, except the last two steps, evaporating the filtrate and redissolving it in water were eliminated. This solution was taken as a $10 \%$ stock solution of natural surfactant and it was diluted as per the requirement. Similar procedure was adopted by Roy et al. [20] for the preparation of natural surfactant solution to understand the enhancement of solubility of hexachlorobenzene and naphthalene.

Characterization of soap nuts fruit pericarp powder: Characteristics of soap nuts fruit pericarp powder was done [47].

Simple absorption spectra: The simple absorption spectra was obtained on 2100 Chemito UV-VIS Spectrophotometer (India). The dye, Congo red (CR) blank was taken as reference i.e. surfactant solution.

The simple absorption spectra of Congo red were obtained in water on 2100 Chemito UV-VIS Spectrophotometer (India) by adapting the following method. The absorption spectra of $0.0203 \mathrm{mM}$ of Congo red without surfactant(s) were obtained in water. To a $25 \mathrm{~mL}$ standard flask, an aliquot of aqueous Congo red solution was added. The required buffer solution was added up to the mark of standard flask and shakes the solution to get uniform concentration.

The simple spectra of $0.0203 \mathrm{mM}$ of Congo red solution containing cationic surfactant, CTAB in the concentration range of 0.4 to $2.0 \mathrm{mM}$, anionic surfactant, SDS in the concentration range of 3 to $17 \mathrm{mM}$, nonionic surfactant, Triton $\mathrm{X}-100$ in the concentration range of 0.012 to $10.016 \mathrm{mM}$ and natural surfactant obtained from soap nuts in the percent range of 0.01 to $10 \%$ were obtained. The concentration of Congo red was kept constant during the whole process. To a $25 \mathrm{~mL}$ standard flask, an aliquot of an aqueous surfactant solution and $1 \mathrm{~mL}$ of $0.5066 \mathrm{mM}$ aqueous Congo red solutions were added. The required buffer solution was added up to the mark of standard flask and shakes the solution to get uniform concentration. This explains the effect of surfactant on the spectra of Congo red.

Similarly, the effect of $\mathrm{pH}$ also obtained by keeping the remaining constant by adapting the same procedure explained above.

\section{RESULTS AND DISCUSSION}

Characteristics of aqueous extract of pericarp of soap nut fruit: The different types of saponins were present in different plant base [48].

Range of molecular weight of saponins: Triterpenoid type saponins were mostly present in the pericarp of the soap nut fruits [31]. The chemical formula for these different types of saponins were reported in the literature $[31,34,40,49,50]$ and shown in the Table-1.

\begin{tabular}{|c|c|}
\hline \multicolumn{2}{|c|}{$\begin{array}{c}\text { TABLE-1 } \\
\text { CHEMICAL FORMULA AND MOLECULAR WEIGHT OF } \\
\text { TRITERPENOID SAPONINS IN THE PERICARP OF } \\
\text { Sapindus mukorossi GAERTEN [Ref. 34] }\end{array}$} \\
\hline Formula & m.w. \\
\hline $\mathrm{C}_{41} \mathrm{H}_{66} \mathrm{O}_{12}$ & 750 \\
\hline $\mathrm{C}_{46} \mathrm{H}_{74} \mathrm{O}_{15}$ & 866 \\
\hline $\mathrm{C}_{48} \mathrm{H}_{76} \mathrm{O}_{17}$ & 924 \\
\hline $\mathrm{C}_{50} \mathrm{H}_{78} \mathrm{O}_{18}$ & 966 \\
\hline $\mathrm{C}_{53} \mathrm{H}_{86} \mathrm{O}_{22}$ & 1074 \\
\hline $\mathrm{C}_{58} \mathrm{H}_{94} \mathrm{O}_{26}$ & 1206 \\
\hline $\mathrm{C}_{59} \mathrm{H}_{92} \mathrm{O}_{25}$ & 1200 \\
\hline
\end{tabular}

The average molecular weight of triterpenoid-type saponins (998) was taken for equilibrium constant calculations of interaction between Congo red and natural surfactant in a similar way to calculate the equilibrium constant between cationic dye, Neutral red and natural surfactant [34]. From MALDITOF-MS spectroscopy, the molecular weight of Sapindus saponin was found to be in the range of 921.5 to 1047.5 [4]. In another report, the reported molecular weight of saponin was in between 719 and 1043 [23].

FTIR analysis of saponins: The FTIR transmittance spectrum of the aqueous reetha solution was analyzed and compared with literature (Table-2).

${ }^{1} \mathrm{H}$ NMR spectrum of sapindus saponin, showed signals for alkyl groups (- $\mathrm{CH}_{3}$ groups) $(\delta 0.9,1.1$ and 1.2$)$, anomeric protons and olifenic protons $(\delta 5.4),-\mathrm{OH}$ groups and hydrogen directly attached to oxygen or nitrogen ( $\delta 3.0$ to 4.6) [51]. The NMR spectra of saponin present in extract of pericarp of soap nuts showed similarities to that of Quillaja saponin.

This was a qualitative of presence of saponin. The main intension of this work was to be used the saponin present in the extract of pericarp of soapnut as a natural surfactant.

pH of aqueous extract of pericarp of soap nut fruits: $\mathrm{pH}$ was a very important parameter in surfactant solutions [7] because a change in $\mathrm{pH}$ of a solution changes the net charge 


\begin{tabular}{lcc}
\hline \multicolumn{3}{c}{ TABLE-2 } \\
FTIR ANALYSIS OF SAPONINS \\
OBTAINED FROM PERICARP OF SOAP NUTS \\
\hline Transmittance spectra of group & Frequency $\left(\mathrm{cm}^{-1}\right)$ & Ref. \\
\hline \multirow{2}{*}{ Hydroxyl group (-OH) stretching } & 3455 & {$[4]$} \\
& 3407 & {$[33]$} \\
& 3370 & {$[2]$} \\
\hline \multirow{2}{*}{ Carbon-hydrogen $\left(-\mathrm{CH}_{2}\right)$ stretching } & 2068 & {$[4]$} \\
& 2918 & {$[33]$} \\
\hline Weak C-H bending of alkanes & 1450 & {$[2]$} \\
\hline Presence of alkynes & 2100 & {$[2]$} \\
\hline \multirow{3}{*}{ C=O stretching } & 1639 & {$[4]$} \\
& 1618 & {$[33]$} \\
\hline \multirow{2}{*}{ C-O stretching of carbinol } & 1650 & {$[2]$} \\
& 1050 & {$[2]$} \\
C $=\mathrm{C}$ & 1062 & {$[4]$} \\
\hline Five member ring ketone & 1045 & {$[33]$} \\
\hline
\end{tabular}

on molecules and hence the repulsive force between them. The $\mathrm{pH}$ of aqueous extract of pericarp of soapnut was acidic in nature and this was probably due to hydrolysis of non-ionic glucuronic groups [20,34]. This solution has a tendency to react with sodium hydroxide and this was further evidence for acidic nature of aqueous extract. Further it explains that the two releasable hydrogens were present on natural surfactant.

Absorption spectra in absence of surfactants: The simple absorption spectra of Congo red in absence of surfactants at various pHs like 1, 4, 7 and 10 were obtained (figures were not shown). As expected, the colour at $\mathrm{pH} 1$ solution was different (blackish blue) due to formation of quininoid structure in the Congo red. The observed $\lambda_{\max }$ for the pHs like 1, 4, 7 and 10 were $575,525,480$ and $490 \mathrm{~nm}$, respectively.

Absorption spectra in presence of cationic (CTAB), anionic (SDS) and non-ionic (TX 100) micelles: The simple absorption spectra of solution of Congo red of $0.0203 \mathrm{mM}$ in presence of cationic (CTAB)/anionic (SDS)/non-ionic (TX 100) micelles at different $\mathrm{pHs}$ like $1,4,7$ and 10 were obtained in aqueous medium and recorded (figures were not shown).

Generally, on addition of surfactant to the solution of Congo red, the $\lambda_{\max }$ may be shifted due to formation of complex between Congo red and surfactant. The range of maxima and the change in maxima at concentration of all surfactants against $\mathrm{pHs}$ of the solution is shown in Table-3.

The ratio, of the absorbance obtained at $\lambda_{\max }$ of the complex formed at different concentrations of all surfactants at various pHs like 1, 4, 7 and 10 to the absorbance obtained at $\lambda_{\max }$ of the solution of Congo red alone was calculated. This ratio was used to find out critical micelle concentration (CMC) of surfactants.

As $510 \mathrm{~nm}$ wavelength was observed at higher concentrations of TX-100 in case of $\mathrm{pH} \mathrm{4,7}$ and 10, it was understood that the formation of complex between Congo red and TX100 and the composition of the complex was the same. It means, the composition of the complex formed between Congo red and TX-100 was independent on the $\mathrm{pH}$ at higher $\mathrm{pHs}$. The nature and composition of the complex formed between Congo red and TX-100 at pH 1 may be different from other $\mathrm{pHs}$ as we have observed a difference $\lambda_{\max }$ at $\mathrm{pH} 1$. Similar type

\begin{tabular}{|c|c|c|c|c|}
\hline \multicolumn{5}{|c|}{$\begin{array}{c}\text { TABLE-3 } \\
\text { ABSORPTION SPECTRA OF CONGO RED IN } \\
\text { THE PRESENCE OF CTAB/SDS/TX 100/NS AT } \\
\text { DIFFERENT pHs, CONGO RED }=0.0203 \mathrm{mM}\end{array}$} \\
\hline $\begin{array}{l}\text { Name of } \\
\text { surfactant }\end{array}$ & $\mathrm{pH}$ & $\begin{array}{l}\text { Range of } \\
\text { maxima } \\
(\mathrm{nm})\end{array}$ & $\begin{array}{l}\text { Change in } \\
\text { maxima } \\
(\mathrm{nm})\end{array}$ & $\begin{array}{l}\text { Concentration of } \\
\text { surfactant to change } \\
\text { the maxima }(\mathrm{mM})\end{array}$ \\
\hline \multirow{4}{*}{ CTAB } & 1 & $580-465$ & 115 & 0.6 \\
\hline & 4 & $525-465$ & 60 & 0.4 \\
\hline & 7 & $480-465$ & 15 & 0.9 \\
\hline & 10 & $490-465$ & 25 & 0.7 \\
\hline \multirow{4}{*}{ SDS } & 1 & $580-595$ & 15 & 3.0 \\
\hline & 4 & $525-545$ & 20 & 5.0 \\
\hline & 7 & $480-495$ & 15 & 7.0 \\
\hline & 10 & $490-495$ & 05 & 5.0 \\
\hline \multirow{4}{*}{ TX 100} & 1 & $580-650$ & 70 & 0.2004 \\
\hline & 4 & $525-510$ & 15 & 0.5210 \\
\hline & 7 & $480-510$ & 30 & 0.4008 \\
\hline & 10 & $490-510$ & 20 & 0.4008 \\
\hline \multirow{4}{*}{$\begin{array}{c}\text { Natural } \\
\text { surfactant }\end{array}$} & 1 & $580-575$ & 15 & $0.1002(0.01 \%)$ \\
\hline & 4 & $525-510$ & 15 & $0.2004(0.02 \%)$ \\
\hline & 7 & $480-510$ & 30 & $5.0100(0.50 \%)$ \\
\hline & 10 & $490-510$ & 20 & $5.0100(0.50 \%)$ \\
\hline
\end{tabular}

of conclusions was made even in case of interactions of Congo red with a neutral or nonionic surfactant, Tween 80 [45]. Therefore, the interaction between Congo red and TX-100 may be understood with the mechanism which was suggested by Hayashi [45] in case of the interactions of Congo red and Tween 80.

Absorption spectra in presence of micelles formed by plant based natural surfactant: The simple absorption spectra of the solution of Congo red of $0.0203 \mathrm{mM}$ in the presence of natural surfactant micelles at different $\mathrm{pHs}$ like 1, 4, 7 and 10 were recorded in aqueous medium. $10 \%$ of natural surfactant was prepared as a stock solution and the test solutions of various concentrations (\%) depending on the requirement were further prepared by using the distilled water.

Effect of pH and concentration (\%) of natural surfactant on interaction of Congo red with natural surfactant: The effect of $\mathrm{pH}$ and concentration $(\%)$ on the absorption spectra of Congo red of $0.0203 \mathrm{mM}$ in presence of various concentrations $(\%)$ of natural surfactant were studied and shown in Fig. 1.

Here, the $\lambda_{\max }$ was shifted towards higher wavelengths in case of all pHs like 1, 7 and 10 except in case of $\mathrm{pH} 4$ where the $\lambda_{\max }$ was shifted towards lower wavelengths. It indicates that the complex was formed between Congo red and natural surfactant. On increasing the concentration (\%) of natural surfactant, the $\lambda_{\max }$ was not reverted back to the original $\lambda_{\max }$ and this explains that no monomers were formed. A complete new complex was formed.

The observed absorbance values on addition of natural surfactant even in low concentrations (\%) of natural surfactant were increasing from that of absence of natural surfactant except $\mathrm{pH} 1$ where the absorbance values were almost all the same absorbance values which were obtained in absence of natural surfactant. It indicates that the Congo red was not solubilized in presence of natural surfactant particularly at $\mathrm{pH} 1$. After crossing $0.1 \%$ of natural surfactant, the absorbance values were increasing with increasing the concentrations (\%) of natural surfactant, in general. Probably, Congo red was solubilized as 



Fig. 1. Absorption spectra of Congo red with variable concentration (\%) of natural surfactant at different $\mathrm{pHs}$; [Congo red] $=0.0203 \mathrm{mM}$

higher absorbance values were observed after $0.1 \%$ of natural surfactant. At lower concentrations (\%) of natural surfactant, the absorbance values were low in case of $\mathrm{pH} 4$ and afterwards (after crossing $0.1 \%$ ); the absorbance values were increasing along with increasing the concentrations (\%) of natural surfactant without changing $\lambda_{\max }$. But in case of $\mathrm{pH} 7$, the absorbance values were increasing even at low concentrations (\%) of natural surfactant up to $0.1 \%$ and after crossing $0.1 \%$ the absorbance values were almost become constant. The similar trend was observed in case of $\mathrm{pH} 10$. The solution of Congo red at $\mathrm{pH} 1$ changes its colour to blackish blue and the colour changed to red on addition of natural surfactant at higher concentrations of natural surfactant. This was mainly due to the disappearance of quininoid structure. The $\lambda_{\max }$ was shifted from $575 \mathrm{~nm}$ to $585 \mathrm{~nm}$ without any crest (peak) at $535 \mathrm{~nm}$ in case of $\mathrm{pH} 1$. The change of $\lambda_{\max }$ was shown in Fig. $1 b$.

The $\lambda_{\max }$ was shifted from 525 to $510 \mathrm{~nm}$ without any crest (peak) at $535 \mathrm{~nm}$ in case of $\mathrm{pH} 4$. The change of $\lambda_{\max }$ was shown in Fig. 1c. The $\lambda_{\max }$ was shifted from $480 \mathrm{~nm}$ to $510 \mathrm{~nm}$ in case of $\mathrm{pH} 7$ on increasing the concentration (\%) of natural surfactant. The $\lambda_{\max }$ was shifted from $490 \mathrm{~nm}$ to $510 \mathrm{~nm}$ in case of $\mathrm{pH} 10$ on increasing concentrations (\%) of natural surfactant.

Similar to TX-100, $510 \mathrm{~nm}$ wavelength was observed at higher concentrations of natural surfactant in case of $\mathrm{pH} 4,7$ and 10. It was understood that the formation of complex between Congo red and natural surfactant and the composition of the complex was the same at all pHs like 4, 7 and 10. Thus, the composition of the complex formed between Congo red and natural surfactant was independent on the $\mathrm{pH}$ at higher $\mathrm{pHs}$. The nature and composition of the complex formed between Congo red and natural surfactant at $\mathrm{pH} 1$ may be different from other pHs as we have observed a different $\lambda_{\max }$ at $\mathrm{pH} 1$. From these observations, the behaviour of the plant based natural surfactant, natural surfactant was almost similar to the behaviour of TX-100 in the interactions of Congo red. Probably, hydrophobic interactions between Congo red and NS/TX-100 were predominant compare to the electrostatic interactions between Congo red and CTAB/SDS. Similar type of hydrophobic interactions between Congo red and neutral or nonionic surfactant, Tween 80 was also observed [45]. As TX-100 was also a neutral or nonionic surfactant, here the interaction between Congo red and TX-100 was similar to interaction between Congo red and Tween 80 . Therefore, the nature of the natural surfactant was like a neutral or nonionic surfactant.

Similar type of conclusions was made even in case of interactions of Congo red with a neutral or nonionic surfactant, Tween 80 [45]. Therefore, the interaction between Congo red and natural surfactant may be understood with the mechanism 
suggested by Hayashi [45] in case of the interactions of Congo red and Tween 80.

The range of maxima and the change in maxima at concentration (\%) of natural surfactant against $\mathrm{pHs}$ of the solution is shown in Table-3. The maximum change was observed at $\mathrm{pH}$ 7. Similarly, the ratio, of the absorbance obtained at $\lambda_{\max }$ of the complex formed at different concentrations (\%) of natural surfactant at various pHs like 1, 4, 7 and 10 to the absorbance obtained at $\lambda_{\max }$ of the solution of Congo red alone was calculated. This ratio was used to calculate $\mathrm{CMC}$ of natural surfactant.

Equilibrium constant of complex formed between Congo red and CTAB/SDS/TX 100/NS: The composition of the complex was to be determined. Whether the composition of the complex was 1:1, 1:2, 2:1 etc., was to be determined. If the composition of the complex was $1: 1$, it was conformed through the modified Benesi-Hilderbrand equation [64] (eqn. 9 ). The graph was made between the concentrations of surfactant and $[\mathrm{S}][\mathrm{D}] \mathrm{l} /\left(\mathrm{dc}-\mathrm{d}_{0}\right)$ was used for the determination of the equilibrium constant and it was confirmed that the composition of the complex was 1:1, if the graph was linear (figures are not shown). The slope and intercept along with regression coefficient which were extracted from figure are shown in Table-4. These two values were used for calculating the equilibrium constant $\left(\mathrm{K}_{\mathrm{c}}\right)$ and molar extinction coefficient $\left(\varepsilon_{\mathrm{c}}\right)$ of the complex and these are shown in Table-4.

The equilibrium constants for some other dyes interacting with $\mathrm{CTAB}$ were mentioned here for understanding the equilibrium constant of Congo red with CTAB. The equilibrium constant for the interaction of fluorescein dye with SDS and CTAB was determined by using Scott equation [52]. The equilibrium constants calculated for the solubilized Congo red in presence of CTAB was following the similar trend of above mentioned reference.

The equilibrium constants for some other dyes interacting with SDS were mentioned here for understanding the equilibrium constant of Congo red with SDS. The equilibrium constant of Neutral red with SDS was calculated [34]. The equilibrium constant of safranine T with SDS, Tween 20, Tween 40, Tween 60, Tween 80 and TX-100 in presence of carbohydrates were calculated [53] by using modified equation of Lang [54]. The equilibrium constant for the interaction of fluorescein dye with SDS and CTAB was determined by using Scott equation [52]. The equilibrium constant for the interaction of phenazinium dyes (phenosafranin (PSF), safranin O (SFO), safranin $\mathrm{T}$ (SFT) and methyl orange (MO)) with TX-100 were determined by using the well known Ketalaar equation [55,56].
Phenosafranin (PSF) forms 1:1 molecular complex with TX100 and SDS (or SLS) [55]. The equilibrium constant for the interaction of rhodamine dye derivatives (rhodamine 123, 4,5dibromorhodamine methyl ester and 4,5-dibromorhodamine $n$-butyl ester) with TX-100 were determined by using the well known Ketalaar equation [57]. Phenosafranin (PSF) forms 1:1 molecular complex with TX-100 and SDS (or SLS) [55]. The binding constants of safranin $\mathrm{O}$ in presence of different surfactants like anionic surfactants like SDS and sodium dodecylsulfonate (SDSo), nonionic surfactants like polyxyethylenesorbitanmonolaurate (Tween 20) and polyoxyethylenedodecylether (Brij 35), cationic surfactants like dodecyltrimethylammonium bromide (DTAB) and zwitterionic surfactant, laurylsulfobetaine (LSB) were calculated by means of Benesi-Hilderbrand equation [58]. The equilibrium constants calculated for the solubilized Congo red in presence of SDS was following the similar trend of above mentioned references.

The equilibrium constants for some other dyes interacting with TX 100 were mentioned here for understanding the equilibrium constant of Congo red with TX 100. The equilibrium or binding constant of safranine T with SDS, Tween 20, Tween 40 , Tween 60, Tween 80 and TX-100 in presence of carbohydrates were calculated [53] by using modified equation of Lang [54]. The equilibrium or binding constant of safranine $T$ in presence of reverse micelles formed by Tween 20, Tween 40, Tween 60, Tween 80 and TX-100 were calculated [59] by using modified equation of Lang [54]. The equilibrium constant for the interaction of phenazinium dyes (phenosafranin (PSF), safranin $\mathrm{O}$ (SFO), safranin T (SFT) and methyl orange (MO)) with TX-100 were determined by using the well known Ketalaar equation $[55,56]$. Phenosafranin (PSF) forms 1:1 molecular complex with TX-100 and SDS (or SLS) [55]. The similar trend was observed in the present investigations.

It was observed that the complex was formed in between Congo red and natural surfactant and the hydrodynamic interactions were predominant in place of electrostatic interactions as Congo red was anionic (Fig. 2 and Table-4).

The following observations are made as follows:

- The equilibrium constant of complex of CR-CTAB was increasing with increasing the $\mathrm{pH}$ of the solution and it indicates that the stability of the complex was increased along with $\mathrm{pH}$ of the solution. The equilibrium constant value for this complex was relatively high because electrostatic interactions were predominant over hydrophobic interactions because anionic dye, Congo red interacting with positive CTAB.

TABLE-4

EQUILIBRIUM CONSTANT $\left(\mathrm{K}_{\mathrm{c}}\right)$ AND MOLAR EXTINCTION COEFFICIENT $\left(\varepsilon_{\mathrm{c}}\right)$ FOR THE INTERACTION OF THE CONGO RED WITH CTAB/SDS/TX 100/NS MICELLES AT DIFFERENT pHs AT MAXIMUM WAVELENGTH. CONGO RED =0.0203 mM

\begin{tabular}{ccccccc}
\hline Surfactant & Solution pH & $\begin{array}{c}\text { Slope }(\mathrm{m}) \\
\left(\times 10^{-5}\right)\end{array}$ & $\begin{array}{c}\text { Intercept }(\mathrm{c}) \\
\left(\times 10^{-8}\right)\end{array}$ & $\mathrm{K}_{\mathrm{c}}\left(\mathrm{L} \mathrm{mol}^{-1}\right)$ & $\begin{array}{c}\varepsilon_{\mathrm{c}}\left(\mathrm{L} \mathrm{mol}^{-1} \mathrm{~cm}^{-1}\right) \\
\left(\times 10^{3}\right)\end{array}$ \\
\hline \multirow{2}{*}{ CTAB } & 1 & 13.344 & 1.5346 & 8695.4 & 20.4230 & 0.9378 \\
& 4 & 12.855 & 0.8182 & 15711.3 & 20.1650 & 0.8858 \\
\hline \multirow{2}{*}{ SDS } & 1 & 0.9171 & 1.8934 & 484.4 & 26.8435 & 0.8513 \\
& 7 & 1.0741 & 10.6430 & 100.9 & 29.3960 & 0.9744 \\
\hline \multirow{2}{*}{ TX 100 } & 1 & 9.2490 & 0.6195 & 14928.8 & 23.9879 & 0.9983 \\
& 7 & 11.0290 & 0.9806 & 11247.2 & 29.0660 & 0.9570 \\
\multirow{2}{*}{ Natural surfactant } & 10 & 14.4960 & 2.2697 & 6386.7 & 36.5074 & 0.9905 \\
\hline
\end{tabular}




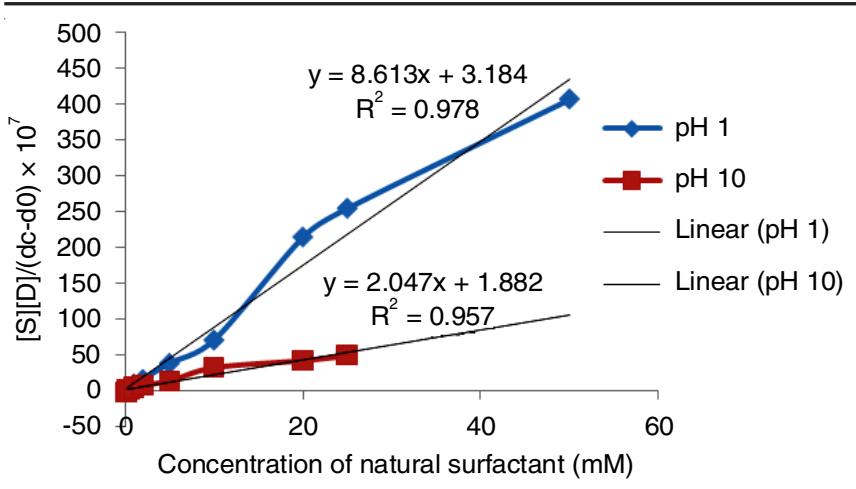

Fig. 2. $[\mathrm{S}][\mathrm{D}] 1 /(\mathrm{dc}-\mathrm{d} 0)$ against $[\mathrm{S}]$ plot for Congo red in natural surfactant micelles at $\mathrm{pH} 1$ and $\mathrm{pH} 10$. Congo red $=0.0203 \mathrm{mM}$

- The equilibrium constant of complex of CR-SDS was decreasing with increasing $\mathrm{pH}$ of the dye solution and it indicates that the stability of the complex was decreased along with $\mathrm{pH}$ of the solution. The value of equilibrium constant for this complex was relatively low because electrostatic interactions were negative (repulsive) due to negative dye, Congo red ion interacting with negative SDS and very weak complex was formed.

- The equilibrium constant of complex of CR-TX 100 was decreasing with increasing $\mathrm{pH}$ of the Congo red solution and it indicates that the stability of the complex was decreased along with $\mathrm{pH}$ of the solution. The value of equilibrium constant for this complex was relatively very high because hydrophobic interaction were predominant over electrostatic interactions to negative dye, Congo red ion interacting with neutral TX 100.

- The equilibrium constant of complex of CR-NS was decreasing with increasing $\mathrm{pH}$ of the Congo red solution and it indicates that the stability of the complex was decreased along with $\mathrm{pH}$ of the solution. The value of equilibrium constant for this complex was relatively low because hydrophobic interaction were predominant over electrostatic interactions to negative dye, Congo red ion interacting with natural surfactant. Similar type of trend was observed in case of complex of Neutral red with natural surfactant [34]. In the same report, it was found that the interaction of Congo red with natural surfactant was thermodynamically favourable.

- The stability of the complexes of Congo red with different surfactants like CTAB, SDS, TX 100 and natural surfactant may be written in increasing order as

\section{CR-TX $100>$ CR-CTAB $>$ CR-NS > CR-SDS}

Suggested mechanism: The mechanism involved in the interaction of Congo red and TX 100 was suggested with respect to the change in $\mathrm{pH}$ of the solutions as follows. In an acidic medium, an acid form of Congo red was equilibrated to a base form (Scheme-I).

The effect of $\mathrm{pH}$ may be interpreted qualitatively by these assumptions as follows. When the $\mathrm{pH}$ of the medium was lowered, the concentration of the base form decreases according to the Scheme-I, which results in an increase of the amount of TX 100, required giving a definite absorbance. The concentrations of the base form become so great that the process was mainly represented by the Scheme-II and the same effect was produced with a smaller amount of TX 100 than that in the acidic medium.

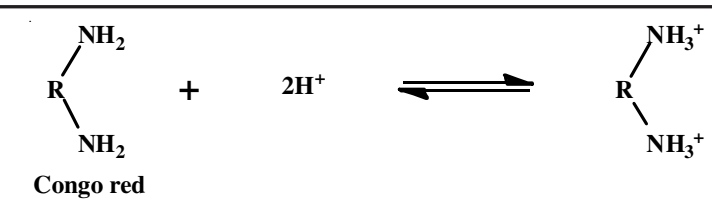

Scheme-I

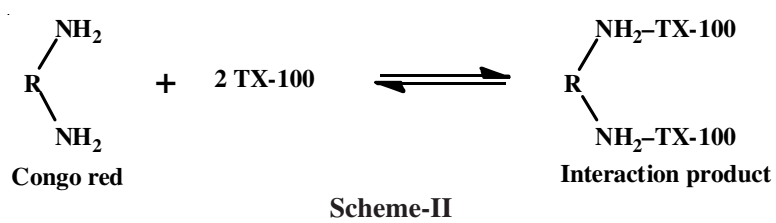

Thus, the amino groups of Congo red were considered to be blocked with TX 100 and the products were well dispersed, since the aggregation of Congo red was prevented by the attachment of TX 100. It was observed that the adsorption of Congo red for filter paper or cotton (which was considered to have a negative surface), was reduced remarkably by the addition of TX 100, which may also be interpreted by a similar process.

The similar mechanism was proposed for the interactions of Congo red with nonionic surfactant, Tween 80 by Hayashi [45].

By using modified Benesi-Hilderbrand equation (eqn. 9), equilibrium constant was calculated within medium concentration range and confirmed that the 1:1 complex was formed. Therefore, some more investigations may be required to confirm the complex composition whether 1:1 or 1:2.

The mechanism was suggested for the interactions of Congo red with TX 100. The same mechanism may be proposed to the interactions of Congo red with natural surfactant also. In place of TX 100, natural surfactant may be taken in the suggested mechanism for TX 100.

Critical micelle concentration (CMC): $\mathrm{CMC}$ was very important characteristics of any surfactant. CMC of CTAB, SDS, TX 100 and natural surfactant was found through spectrophotometric investigations i.e., by using absorbance and absorbance ratio values.

CMC of CTAB: By close observation of the figures, which were drawn between concentration of CTAB and absorbance for the solution of Congo red at different pHs like 1, 4, 7 and 10 , the following conclusions were drawn (figures are not shown).

Very slight changes were observed in case of absorbance values of the solutions. However, there was some trend in identifying the CMC. The absorbance values were increasing or decreasing along with increasing the concentrations of CTAB and some where some sort of intersecting point was identified as CMC of CTAB. These values were observed as 1, 0.8, 0.6 and $1.1 \mathrm{mM}$ for different $\mathrm{pHs}$ of $1,4,7$ and 10 , respectively (Table-5).

The absorbance ratio between the absorbance observed at $\lambda_{\max }$ of the complex and the absorbance observed at $\lambda_{\max }$ of the Congo red alone was used to understand the CMC of CTAB. The graphs which were made between the concentrations of $\mathrm{CTAB}$ and the absorbance ratio were used for identifying the CMC of CTAB at different pHs of solution of Congo red of $0.0203 \mathrm{mM}$. Here also, very slight changes were observed in 


\begin{tabular}{|c|c|c|c|}
\hline \multicolumn{4}{|c|}{$\begin{array}{c}\text { TABLE-5 } \\
\text { CMC (mM) Of CTAB, SDS, TX } 100 \text { and NATURAL } \\
\text { SURFACTANT AT VARIOUS pHs OF SOLUTION } \\
\text { OF CONGO RED OF } 0.0203 \mathrm{mM}\end{array}$} \\
\hline \multirow{2}{*}{ Surfactant } & \multirow{2}{*}{$\mathrm{pH}$} & \multicolumn{2}{|c|}{$\mathrm{CMC}(\mathrm{mM})$} \\
\hline & & Absorbance & Absorbance ratio \\
\hline \multirow{4}{*}{ CTAB } & 1 & 1.0 & 0.8 \\
\hline & 4 & 0.8 & 0.8 \\
\hline & 7 & 0.6 & 0.6 \\
\hline & 10 & 1.1 & 1.1 \\
\hline \multirow{4}{*}{ SDS } & 1 & 7 & 7 \\
\hline & 4 & 9 & 10 \\
\hline & 7 & 9 & 12 \\
\hline & 10 & 11 & 10 \\
\hline \multirow{4}{*}{ TX 100} & 1 & 0.2 & 0.2 \\
\hline & 4 & 0.3 & 0.3 \\
\hline & 7 & 0.3 & 0.2 \\
\hline & 10 & 0.3 & 0.3 \\
\hline \multirow{4}{*}{$\begin{array}{c}\text { Natural } \\
\text { surfactant }\end{array}$} & 1 & $0.02(\%)$ & $0.02(\%)$ \\
\hline & 4 & $0.10(\%)$ & $0.02(\%)$ \\
\hline & 7 & $0.02(\%)$ & $0.10(\%)$ \\
\hline & 10 & $0.05(\%)$ & $0.05(\%)$ \\
\hline
\end{tabular}

case of absorbance ratio values of the solutions. However, there was some trend in identifying the CMC. The absorbance ratio values were increasing or decreasing along with increasing the concentrations of CTAB and somewhere some sort of inte-
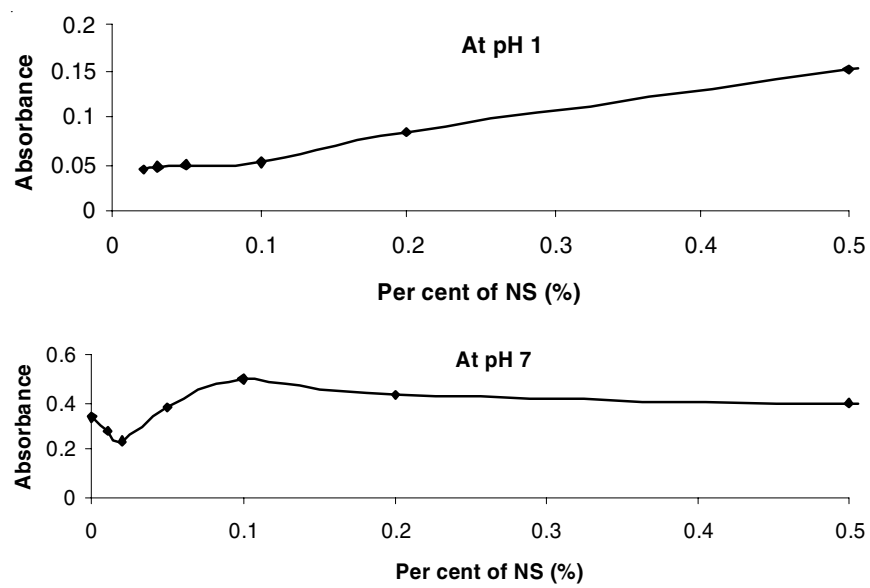

resting point was identified as CMC of CTAB. The absorbance ratio values along with different concentrations of CTAB at different $\mathrm{pHs}$ like 1, 4, 7 and 10 (figures are not shown). These values were observed as $0.8,0.8,0.6$ and $1.1 \mathrm{mM}$ for $\mathrm{pHs}$ of 1, 4, 7 and 10, respectively (Table-5). The CMC of CTAB (calculated by using absorbance and absorbance ratio) as shown in Table-5 at various pHs were within the range of reported values in the literature.

CMC of SDS and TX 100: Similar to CTAB, the CMC of SDS and TX 100 were also obtained from the graphs plotted between absorbance/absorbance ratio and concentration of surfactant (Graphs were not shown here) and the values are shown in Table-5. The CMC of SDS and TX 100 shown in Table-5 at various $\mathrm{pHs}$ were within the range of reported values in the literature.

CMC of natural surfactant: The CMC of natural surfactant was also calculated from the graphs plotted between absorbance/absorbance ratio and \% natural surfactant as shown in Figs. 3 and 4. The CMC values of natural surfactant at various pHs are shown in Table-5.

The CMC of natural surfactant reported in the literature is shown in Table-6. The values obtained in this study were within the stipulated values.

As seen in Table-6, very high CMC values were also observed. In those research studies, no extraction procedure
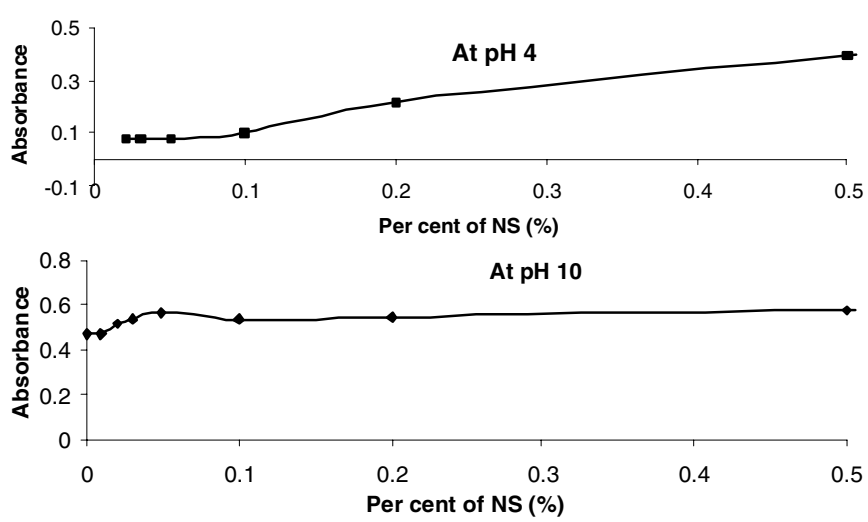

Fig. 3. Absorbance of the solution of Congo red and natural surfactant as a function of $\%$ natural surfactant at various pHs at. Congo red $=$ $0.0203 \mathrm{mM}$


Fig. 4. Ratio of absorbance of the solution of Congo red and natural surfactant as a function of $\%$ natural surfactant at various pHs. Congo red $=0.0203 \mathrm{mM}$ 


\begin{tabular}{lcc}
\hline \multicolumn{3}{c}{ TABLE-6 } \\
\multicolumn{3}{c}{ REPORTED CMC VALUES OF NATURAL } \\
SURFACTANT IN THE LITERATURE \\
\hline \multicolumn{1}{c}{ Technique used } & CMC & Ref. \\
\hline Conductivity $(\%)$ & \\
Spectrophotometry (absorbance) & $0.04-0.05$ & {$[33]$} \\
Surface tension & 0.045 & \\
Conductivity & 0.03 & {$[34]$} \\
Surface tension & $0.1-0.12$ & {$[2]$} \\
Surface tension & $0.08-0.1$ & {$[37]$} \\
Surface tension & 2.3 & {$[4]$} \\
Surface tension & 0.75 & {$[4,60]$} \\
Surface tension & 0.1 & {$[20,61]$} \\
Surface tension & 1.7 & \\
Viscosity & 0.1 & This study \\
Spectrophotometry (absorbance) & $0.02-0.5$ \\
\hline
\end{tabular}

was followed. These differences may be due to fact that the extract was not constituted purely of saponin and different chemical compounds present in the extract along with saponin may interact with saponin. It was observed that the $\mathrm{CMC}$ values of non-ionic surfactants, in general, were smaller than that of ionic surfactants [62] due to ion-ion head group repulsion [63]. It was already observed that the natural surfactant was nonionic surfactant and again it was proved from CMC values as it has low CMC values.

\section{Conclusion}

The saponin natural surfactant obtained from plant based soapnut pericarp was introduced in place of synthetic surfactants successfully. This natural surfactant/boi-surfactant have more advantages like biodegradable, eco-friendly, low toxic, low cost, biocompatible, renewable, higher foaming capacity etc. over synthetic surfactants. The nature of this surfactant was understood through spectrophotometric interactions with Congo red and by comparing these spectrophotometric studies with that of commercial surfactants like cationic surfactant cetyl trimethylammonium bromide (CTAB), anionic surfactant - sodium dodecyl sulphate (SDS) and neutral or non-ionic surfactant - Triton X 100 (TX 100) for understanding the nature of natural saponin. The interactions between Congo red and non-ionic surfactants, TX 100 and Tween 80 [45] were very similar to that of Congo red with saponin natural surfactant (NS) and therefore the nature of introduced natural surfactant may be similar to non-ionic surfactant. The mechanism of these interactions was suggested.

Complex between Congo red and surfactant was formed and the equilibrium constant $\left(\mathrm{K}_{\mathrm{c}}\right)$ and molar extinction coefficient $\left(\varepsilon_{c}\right)$ of the complexes formed between Congo red and all surfactants (CTAB, SDS, TX 100 and natural surfactant) were determined by using modified form of the Benesi-Hildebrand equation [64]. As per the calculated equilibrium constant values, 1:1 complex was formed for Congo red with all surfactants. But this was contrary to the mechanism suggested because 1:2 complexes were formed as per the suggested mechanism. Therefore, some more investigations may be required to confirm the complex composition whether 1:1 or 1:2.

The stability of the complexes of Congo red with different surfactants like CTAB, SDS, TX 100 and natural surfactant was written in increasing order as:
CR-TX $100>$ CR-CTAB > CR-NS > CR-SDS

This spectrophotometric data was used to find out micellar characteristics of saponin such as critical micellar concentration $(\mathrm{CMC})$ of all surfactants. The $\mathrm{CMC}$ value of natural surfactant obtained from these investigations was within the range documented in the literature. Very high CMC values were also observed. In those research studies, no extraction procedure was followed, these differences may be due to fact that the extract was not constituted purely of saponin and different chemical compounds present in the extract along with saponin may interact with saponin. It was observed that the $\mathrm{CMC}$ values of non-ionic surfactants, in general, were smaller than that of ionic surfactants [62] due to ion-ion head group repulsion [63]. It was already observed that the natural surfactant was nonionic surfactant and again it was proved from CMC values as it has low CMC values.

\section{ACKNOWLEDGEMENTS}

The authors were grateful to the AICTE (All India Council for Technical Education, New Delhi) for the financial assistance to establish the infrastructure required to carry out the present research work. The authors were also grateful to the Management, the Director and the Principal of G.P.R. Engineering College (Autonomous), Kurnool for their constant encouragement and help.

\section{CONFLICT OF INTEREST}

The authors declare that there is no conflict of interests regarding the publication of this article.

\section{REFERENCES}

1. R.H. Ottewill, ed.: Th.F Tadros, Introduction in 'Surfactants', Academic Press: London, Chap. 1, pp. 1-18 (1984).

2. A. Basu, S. Basu, S. Bandyopadhyay and R. Chowdhury, Ind. Crops Prod., 77, 920 (2015); https://doi.org/10.1016/j.indcrop.2015.10.006.

3. T. Yadav, D. Tikariha, J. Lakra, M.L. Satnami, A.K. Tiwari, S.K. Saha and K.K. Ghosh, J. Mol. Liq., 204, 216 (2015); https://doi.org/10.1016/j.molliq.2015.01.015.

4. K. Samal, C. Das and K. Mohanty, Dyes Pigments, 140, 100 (2017); https://doi.org/10.1016/i.dyepig.2017.01.031.

5. C. Schmitt, B. Grassl, G. Lespes, J. Desbrieres, V. Pellerin, S. Reynaud, J. Gigault and V.A. Hackley, Biomacromolecules, 15, 856 (2014); https://doi.org/10.1021/bm401708m.

6. U. Zoller, Environ. Int., 32, 269 (2006); https://doi.org/10.1016/j.envint.2005.08.023.

7. L. Tmakova, S. Sekretar and S. Schmidt, Chem. Pap., 70, 188 (2016); https://doi.org/10.1515/chempap-2015-0200.

8. A. Pradhan and A. Bhattacharyya, J. Surf. Sci. Technol., 30, 59 (2014); https://doi.org/10.18311/jsst/2014/1856.

9. J. Jensen, Sci. Total Ennviron., 226, 93 (1999); https://doi.org/10.1016/S0048-9697(98)00395-7.

10. R.P. Singh, N. Gupta, S. Singh, A. Singh, R. Suman and K. Annie, Bull. Environ. Contam. Toxicol., 69, 265 (2002); https://doi.org/10.1007/s00128-002-0056-z.

11. T. Cserhati, E. Forgacs and G. Oros, Environ. Int., 28, 337 (2002); https://doi.org/10.1016/S0160-4120(02)00032-6.

12. Y. Chevalier, Curr. Opin. Colloid Interface Sci., 7, 3 (2002); https://doi.org/10.1016/S1359-0294(02)00006-7.

13. C. Edser, Focus Surfactant, 5, 1 (2006).

14. T. Ivankovic and J. Hrenovic, Arh. Hig. Rada Toksikol., 61, 95 (2010); https://doi.org/10.2478/10004-1254-61-2010-1943.

15. N.R. Biswal and S. Paria, RSC Adv., 4, 9182 (2014); https://doi.org/10.1039/c3ra41876f. 
16. A. Samanta, K. Ojha, A. Madal and A. Sarkar, J. Pet. Eng. Technol., 3, 20 (2013).

17. K. Holmberg, Curr. Opin. Colloid Interface Sci., 6, 148 (2001); https://doi.org/10.1016/S1359-0294(01)00074-7.

18. S. Salati, C. Papa and F. Adani, Biotechnol. Adv. 29, 913 (2011); https://doi.org/10.1016/j.biotechadv.2011.07.012.

19. I. Johansson and M. Svensson, Curr. Opin. Colloid Interface Sci., 6, 178 (2001); https://doi.org/10.1016/S1359-0294(01)00076-0.

20. D. Roy, R.R. Kommalapati, S.S. Mandava, K.T. Valsaraj and W.D. Constant, Environ. Sci. Technol., 31, 670 (1997); https://doi.org/10.1021/es960181y.

21. M.A. Berhow, E.D. Wagner, S.F. Vaughn and M.J. Plewa, Mutat. Res., 448, 11 (2000); https://doi.org/10.1016/S0027-5107(99)00225-0.

22. S. Mitra and S.R. Dungan, J. Agric. Food Chem., 45, 1587 (1997); https://doi.org/10.1021/jf960349z.

23. K.H. Shaker, M. Bernhardt, M.H.A. Elgamal and K. Seifert, Phytochemistry, 51, 1049 (1999); https://doi.org/10.1016/S0031-9422(98)00750-X.

24. Ö. Güçlü-Üstündag and G. Mazza, Crit. Rev. Food Sci. Nutr., 47, 231 (2007); https://doi.org/10.1080/10408390600698197.

25. S. Yin, J. Chen, S. Sun, C. Tang, Y. Yang, Q. Wen and J. Qi, J. Food Chem., 128, 420 (2011); https://doi.org/10.1016/j.foodchem.2011.03.046.

26. R.R. Kommalapati, K.T. Valsaraj, W.D. Constant and D. Roy, J. Hazard. Mater, 60, 73 (1998); https://doi.org/10.1016/S0304-3894(97)00156-8.

27. N. Singh, A. Kaur and K. Yadav, Nat. Sci., 8, 41 (2010).

28. M. Banerjee, A. Hazra, Y.P. Bharitkar and N.B. Mondal, J. Fert.: in vitro IVF-Worldwide Reprod. Med. Genet. Stem Cell Biol., 3, 1 (2014); https://doi.org/10.4172/2375-4508.1000138.

29. P. Tiwari, D. Singh and M.M. Singh, J. Antimicrob. Chemother, 62, 526 (2008); https://doi.org/10.1093/jac/dkn223.

30. C.Y. Cheok, H.A.K. Salman and R. Sulaiman, Food Res. Int., 59, 16 (2014); https://doi.org/10.1016/j.foodres.2014.01.057.

31. R. Li, Z.L. Wu, Y.J. Wang and L.L. Li, Ind. Crops Prod., 51, 163 (2013); https://doi.org/10.1016/j.indcrop.2013.08.079.

32. W. Zhou, X. Wang, C. Chen and L. Zhu, Colloids Surf. A Physicochem. Eng. Asp., 425, 122 (2013); https://doi.org/10.1016/j.colsurfa.2013.02.055.

33. S. Balakrishnan, S. Varughese and A.P. Deshpande, Tenside Surf. Det., 43, 262 (2006); https://doi.org/10.3139/113.100315.

34. S.-T. Muntaha and M.N. Khan, J. Clean. Prod., 93, 145 (2015); https://doi.org/10.1016/j.jclepro.2015.01.023.

35. M.N. Kumar, B. Govindh and N. Annapurna, Asian J. Chem., 29, 2541 (2017); https://doi.org/10.14233/ajchem.2017.20842A.

36. V. Reddy, R.S. Torati, S. Oh and C.G. Kim, Ind. Eng. Chem. Res., 52, 556 (2013); https://doi.org/10.1021/ie302037c.

37. A. Pradhan and A. Bhattacharyya, J. Clean. Prod., 150, 127 (2017); https://doi.org/10.1016/j.jclepro.2017.03.013.

38. K. Urum and T. Pekdemir, Chemosphere, 57, 1139 (2004); https://doi.org/10.1016/j.chemosphere.2004.07.048.

39. S. Song, L. Zhu and W. Zhou, Environ. Pollut., 156, 1368 (2008); https://doi.org/10.1016/j.envpol.2008.06.018.
40. A.B. Chhetri, K.C. Watts, M.S. Rahman and M.R. Islam, Part A, 31, 1893 (2009).

41. K.J. Rao and S. Paria, J. Phys. Chem. B, 113, 474 (2009); https://doi.org/10.1021/jp8071298.

42. J. Singh, S. Sinha, N. Batra and A. Joshi, Environ. Technol., 33, 349 (2012); https://doi.org/10.1080/09593330.2011.572925.

43. M.B. Sarma, S.B. Gogoi, D. Devi and B. Goswami, J. Sci. Ind. Res., 71, 270 (2012).

44. S. Khandelwal and Y.R. Chauhan, J. Chem. Pharm. Res., 4, 4219 (2012).

45. M. Hayashi, Bull. Chem. Soc. Jpn, 34, 119 (1961); https://doi.org/10.1246/bcsj.34.119

46. D.D. Perrin, B. Dempsey, Buffers for $\mathrm{pH}$ and Metal Ion Control, Springer: Netherlands, pp 128-134, 197 (1974).

47. M.C. Somasekhara Reddy, K. Sridevi, S.M. Sarvar Jahan and G.V. Subba Reddy, Asian J. Chem., 31, 89 (2019); https://doi.org/10.14233/ajchem.2019.21523.

48. J.-P. Vincken, L. Heng, A. de Groot and H. Gruppen, Phytochemistry, 68, 275 (2007); https://doi.org/10.1016/j.phytochem.2006.10.008.

49. H. Huang, S. Liao, F. Chang, Y. Kuo and Y. Wu, J. Agric. Food Chem., 51, 4916 (2003): https://doi.org/10.1021/jf0301910.

50. H. Huang, M. Wu, W. Tsai, S. Liao, C. Liaw, L. Hsu, Y. Wu and Y. Kuo, Phytochemistry, 69, 1609 (2008); https://doi.org/10.1016/j.phytochem.2007.10.033.

51. N.T. Nyberg, H. Baumann and L. Kenne, Anal. Chem., 75, 268 (2003); https://doi.org/10.1021/ac025725v.

52. S. Biswas, S.C. Bhattacharya, P.K. Sen and S.P. Moulik, J. Photochem. Photobiol. A:Chem., 123, 121 (1999); https://doi.org/10.1016/S1010-6030(99)00028-3.

53. K.R. Acharya, S.C. Bhattacharyya and S.P. Moulik, J. Photochem. Photobiol. Chem., 122, 47 (1999); https://doi.org/10.1016/S1010-6030(99)00003-9.

54. R.P. Lang, J. Am. Chem. Soc., 84, 1185 (1962); https://doi.org/10.1021/ja00866a025.

55. K.K. Rohatgi-Mukherjee, R. Chaudhuri and B.B. Bhowmik, J. Colloid Surf. Sci., 106, 45 (1985); https://doi.org/10.1016/0021-9797(85)90378-9.

56. J.A.A. Ketelaar, C. van de Stolpe, A. Goudsmit and W. Dzcubas, Recl. Trav. Chim. Pays Bas, 71, 1104 (1952); https://doi.org/10.1002/recl.19520711108.

57. P. Pal, H. Zeng, G. Durocher, D. Girard, D. Giasson, L. Blanchard, L. Gaboury and L. Villeneuve, J. Photochem. Photobiol. Chem., 98, 65 (1996); https://doi.org/10.1016/1010-6030(96)04351-1.

58. S. Gokturk and M. Tuncay, Spectrochim. Acta, 59, 1857 (2003); https://doi.org/10.1016/S1386-1425(02)00418-3.

59. S.C. Bhattacharya, S. Nandi and S.P. Moulik, J. Photochem. Photobiol. Chem., 97, 57 (1996); https://doi.org/10.1016/1010-6030(96)04308-0.

60. R. Ghagi, S.K. Satpute, B.A. Chopade and A.G. Banpurkar, Indian J. Sci. Technol., 4, 530 (2011).

61. R.R. Kommalapati, K.T. Valsaraj, W.D. Constant and D. Roy, Water Res., 31, 2161 (1997); https://doi.org/10.1016/S0043-1354(97)00052-3.

62. N.A. Negm and A.S. Mohamed, J. Surfactants Deterg., 7, 23 (2004); https://doi.org/10.1007/s11743-004-0284-z.

63. P.K. Sansanwal, J. Sci. Ind. Res., 65, 57 (2006).

64. H.A. Benesi and J.H. Hildebrand, J. Am. Chem. Soc., 71, 2703 (1949); https://doi.org/10.1021/ja01176a030. 